\title{
Integration of various Quality Management Systems in Clinical Trials: A Perspective
}

\author{
Article by Pramod Wable ${ }^{\mathrm{a}}$, Prithpal Sing Matrej ${ }^{\mathrm{b}}$, Barney Horne ${ }^{\mathrm{c}}$, Manoj Jadhav ${ }^{\mathrm{d}}$ \\ ${ }^{\mathrm{a}} \mathrm{PhD}$ student from Texila American University \\ ${ }^{\mathrm{b}}$ Department of Pharmacology, Gian Sagar Medical College and Hospital \\ ${ }^{\mathrm{c}}$ Department of Quality Assurance GCP_GLP, Daiichi Sankyo Development Ltd. \\ ${ }^{\mathrm{d}}$ Division of Cardiology, College of Medicine \\ Email: pjwable@gmail.com
}

\begin{abstract}
Background: In clinical trials, turnaround time, data accuracy and quality are critical for developing safe and new medicine for patients. The cost of a one-day delay in a drug being brought to the market can be in millions. ${ }^{1}$ It is essential; therefore, that all stakeholders in clinical trials take steps forward to improve efficiency, accuracy and quality of the clinical research overall. Doing so requires that organizations look beyond symptoms to uncover the true causes of errors in quality and delays. Additionally, new processes must be implemented in such a way as to become part of institutional culture, ensuring the consistent, on-going success of future efforts.

Purpose/Aim: To integrate, study and develop a stable, robust and reproducible Quality Management System (QMS) using combined quality management techniques such as Six Sigma, ISO and Lean together in clinical research.

Methods: Group of Students and working professionals will be asked to assess these three techniques individually and combined using pre-defined, developed and validated paper questionnaires. Different studies will be conducted over the period of 6-18 months and data will be collected. These studies will have an objective of testing each of three techniques on established processes to see if these can be used for process improvements. Result of these studies and quality matrix will be looked at to see how Six Sigma, ISO and Lean work independently and in combination of each other at the same time. Validated questionnaires will be used to obtain the results. Any survey tool developed will be piloted before using in the main phase of the study. Model needs will vary according to level of accessibility and sub-techniques, and this will need to be considered when selecting the sample for detailed study. Standard statistical packages will be used for examination. Standard qualitative and qualitative data analysis software package will be used to interpret the data generated form the review, questionnaire and interviews.

Conclusions: It is expected from proposed studies that combined use of ISO, Lean and Six Sigma techniques can improve quality of processes, data and produce robust Quality Management System.

These three techniques are different but complement each other. It is anticipated that a combination of these techniques will be of a great magnitude and beneficial to clinical research.

Keywords: Integration, ISO, Lean, Six Sigma, Quality Management System, Clinical Research Introduction

Analysis of data available on clinicaltrials.gov - a service of the U.S. National Institutes of Health, shows that there was an approximate 28 fold increase in the total number of clinical trials registered in 2013 (159,318 studies) compared to year 2000 (5635 studies).2 Following figure 1 shows rapid growth in the registered clinical trials over last 13 years. With increased number of
\end{abstract}


clinical trials; key parameters of clinical research such as cost of conducting trials and patient safety had increased pressure on quality and for improved QMS.

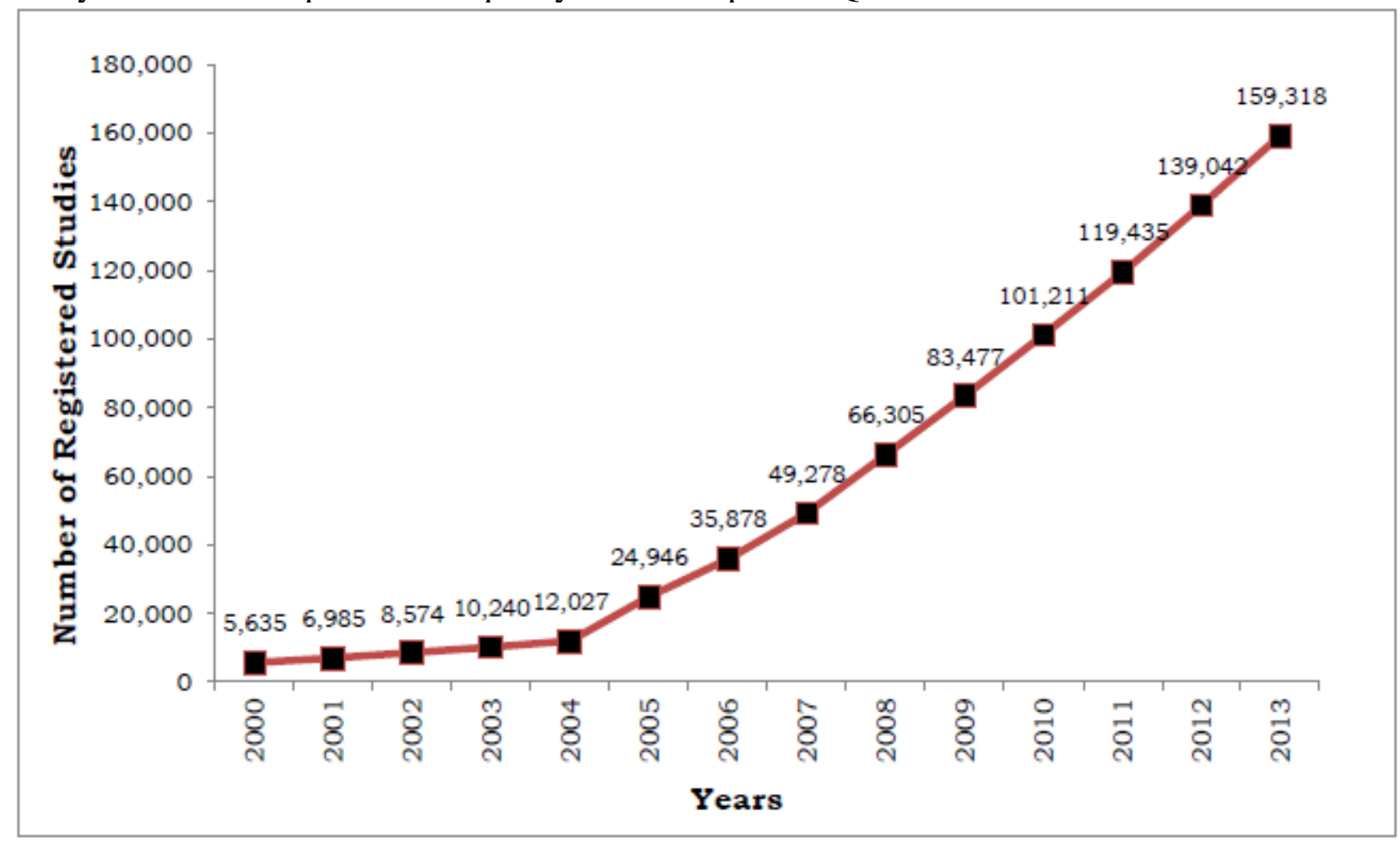

Figure 1. Number of registered clinical studies over last 13 years on clintrials.gov

In current scenario of clinical trials with increase in regulatory demands, globalization, outsourcing and complexity of clinical trials have raised the bar of achieving global quality within clinical research. There is a growing effort to have established quality systems in place during the planning and execution stages of clinical trials. These quality systems require thorough planning, development and implementation of standards during each step. The quality of the clinical research is judged by regulatory inspections of investigator sites, sponsors and contract research organizations. A systematic approach will produce a more reliable and useful end product with high-quality data without compromising the protection of human subjects' rights and welfare.3

Quality Management Systems in Clinical Research can be described as the authority to provide a solution for the challenges in development of the medicinal product or process while assuring safety for human subjects and patients.

Within current clinical scenario, there are different models of QMS in use. Organizations are trying to develop internal systems based on their processes and advancement; however this has raised many challenges with increase in demand for quality. There are number of activities that QA is involved as a part of clinical research team at current situation. QA is involved to provide input from setting up a clinical trial to post trial activities until that investigational product is launched in the market. Organizations are trying to implement established quality systems such as ISO, Six Sigma et.al but facing difficulties due to lack of their use in clinical research before. Implementing robust QMS always has some challenges. Manpower or additional resources is key hurdle for most of the organizations as this is directly linked to additional budget - costing more money to organization. Too many defined processes and procedures hinder deliverables. Advanced new technologies, electronic data capture and intense data review also contribute in 
defining and developing user required QMS. Where special and adaptive clinical study designs, modern statistics and stimulation experiments are improving standard of clinical research; increasingly tight regulatory requirements and recent risk based approach are demanding accurate and robust QMS. (Cynthis F, et.al, 2010)

To fulfil the requirements and improve the quality with no additional challenges and cost; we propose following perspective of the Quality Management System to be used in clinical research.

The proposed perspective of Quality management System aims the use of combined techniques such as Six Sigma, ISO and Lean together to establish stable, high standard and precise Quality Management System within clinical research.

Following figure 2 shows a hypothetical model using three techniques in proposed perspective of quality management system.

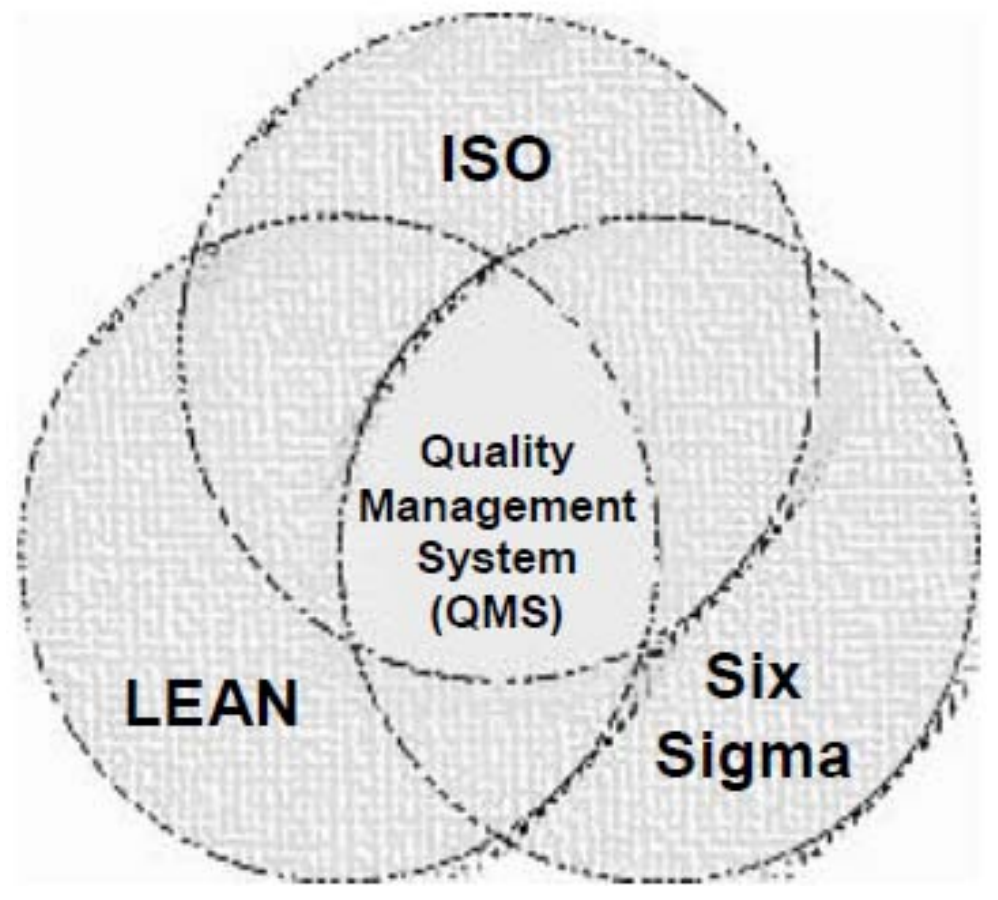

Figure 2. Integration of six sigma, ISO and lean

As shown in figure 2, probably the best thing to learn that these three approaches are not exclusive. If you're interested in Six Sigma, that doesn't prevent you from looking into Lean. If you're pursuing ISO certification, that doesn't mean you must avoid Six Sigma. All three approaches offer advantages, and they complement each other. Importantly there is no need to invest additional man power, money and technology for each of three techniques with this approach as they mutually benefit to each other. Within current highly competitive and regulated clinical research industry, it will be added advantage to apply this approach in Quality Management System. Table 1 below shows the comparison of these three techniques on core aspects to describe that they are mutually beneficial to each other. There are similarities in the application of these techniques which makes integration achievable and sustainable. 
South American Journal of Clinical Research

Special Edition 2016

Table 1 Comparison of six sigma, ISO and lean principles5, 6, 7

\begin{tabular}{|c|c|c|c|}
\hline & Six Sigma & ISO & Lean \\
\hline Goal & $\begin{array}{l}\text { Improve } \quad \begin{array}{r}\text { process } \\
\text { capability }\end{array} \text { and } \\
\text { eliminate/minimize } \\
\text { variation }\end{array}$ & $\begin{array}{l}\text { Help organizations } \\
\text { ensure that they } \\
\text { meet the needs of } \\
\text { customers and other } \\
\text { stakeholders while } \\
\text { meeting statutory } \\
\text { and regulatory } \\
\text { requirements }\end{array}$ & $\begin{array}{l}\text { Understand process } \\
\text { flow and eliminate } \\
\text { waste }\end{array}$ \\
\hline Application & $\begin{array}{l}\text { Any } \\
\text { process }\end{array}$ & $\begin{array}{l}\text { Any } \\
\text { process }\end{array}$ & $\begin{array}{l}\text { Primarily high } \\
\text { volume processes }\end{array}$ \\
\hline Project Selection & $\begin{array}{l}\text { Gap analysis or } \\
\text { business process } \\
\text { mapping }\end{array}$ & QMS & $\begin{array}{l}\text { Locally driven as } \\
\text { needed }\end{array}$ \\
\hline Infrastructure & $\begin{array}{l}\text { Dedicate resource } \\
\text { e.g. Quality } \\
\text { Assurance }\end{array}$ & $\begin{array}{lr}\text { Dedicated } & \text { resource } \\
\text { e.g. } & \text { Quality } \\
\text { Assurance } & \\
\end{array}$ & $\begin{array}{lr}\text { Minimum } & \text { resource } \\
\text { e.g. } & \text { Quality } \\
\text { Assurance } & \\
\end{array}$ \\
\hline Training Required & $\begin{array}{l}\text { Learning by doing } \\
\text { or classroom }\end{array}$ & $\begin{array}{l}\text { Learning by doing } \\
\text { or classroom }\end{array}$ & $\begin{array}{l}\text { Learning by doing } \\
\text { or classroom }\end{array}$ \\
\hline
\end{tabular}

Our research model will use questionnaires which combine three techniques to obtain mainly qualitative responses from users, complemented by interviews and focus groups. The initial target is to gather current subjective and quantitative data on the quality systems of the clinical research. Accessibility of models will be also tested and quality management systems' matrix will be looked at to assess the impact of each of the individual models. Any survey tool developed will be piloted before using in the main phases of the processes. The drive of pilot is to assess if developed tool/questionnaire serves the purpose of the experiment before using it on large scale. Model needs will vary according to level of accessibility and sub-techniques, and this will be considered when selecting the sample for detailed study.

In conclusion, if integrated, Six Sigma, ISO and Lean proponents claim that its benefits may include significant process cycle-time reduction resulting reducing the cost. In 2006, Elliott Liu demonstrated that $70 \%$ cycle-time can be reduced using six sigma technique alone in Case Report Form data entry process. 4 With less waste of materials and efforts, better understanding of customer requirements, it is anticipated that customer satisfaction will be improved by more reliable processes, services and products. This could be the highlight of the proposed integration.

These three models have ability to work together and come up with robust QMS to produce accurate and scientifically proven clinical results with improved quality.

Six Sigma, ISO and Lean also have direct impact on society by improving the quality of clinical research and delivering high quality medicines to society - the end users. When there will be stable and improved quality management system in the clinical research; it will provide high quality of research results and precise scientific value of trials. It will have positive impact on the patients taking part in clinical trials improving patient safety, well-being and data integrity. This combine system of three techniques will eventually improve quality of life and better medicine for patients.

\section{Declaration of conflicting interests}

'The Author(s) declare(s) that there is no conflict of interest'. 


\section{South American Journal of Clinical Research \\ Special Edition 2016}

\section{Reference}

[1]. $\quad$ Applie

Clinical Trials; $\quad$ Retrieved

on

$06 \quad$ October

2014,

http://www.appliedclinicaltrialsonline.com/appliedclinicaltrials/article/articleDetail.jsp?id=791938; Dawn Pope; Lean Six Sigma in the Clinical Trial Industry: Two Perspectives, published on 09 October 2012

[2]. ClinicalTrials.gov; Retrieved on 06 October 2014, https://clinicaltrials.gov/ct2/resources/trends

[3]. International Conference on Harmonization (ICH); Good Clinical Practice (GCP) E6 - Guidelines; retrieved on 06 October 2014, http://www.ich.org/fileadmin/Public_Web_Site/ICH_Products/Guidelines/Efficacy/E6/E6_R1_Guideline.pdf

[4]. Lui EW. Clinical research: the Six Sigma way. J Assn Lab Automat 2006;11(1):42-49.

[5]. Chow-Chua, Clare; Goh, Mark; Wan, Tan Boon (2003). "Does ISO 9000 certification improve business performance?". International Journal of Quality \& Reliability Management 20 (8): 936.

[6]. Cynthis F. Kleppinger; Leslie K. Ball. Building Quality in Clinical Trials With Use of Quality Systems Approach; Journal of Clinical Infectious Diseases 2010; 51(S1):S111-S116.

[7]. Zidel, Tom (2006), A Lean Guide to Transforming Healthcare ISBN 0-87389-701-3 